\title{
Attrition of Surgical Faculty in an Academic Medical Center
}

\author{
Bhagwan Satiani1 $^{*}$, David Way², Heather Brod ${ }^{3}$, E. Christopher Ellison'1, Thomas E. Williams ${ }^{1}$ \\ ${ }^{1}$ Departments of Surgery, Wexner Medical Center, The Ohio State University College of Medicine, Columbus, Ohio, USA \\ ${ }^{2}$ Emergency Medicine, Wexner Medical Center, The Ohio State University College of Medicine, Columbus, Ohio, USA \\ ${ }^{3}$ Faculty Affairs, Wexner Medical Center, The Ohio State University College of Medicine, Columbus, Ohio, USA \\ Email: ^bhagwan.satiani@osumc.edu
}

How to cite this paper: Satiani, B., Way, D., Brod, H., Ellison, E. C., \& Williams, T. E. (2017). Attrition of Surgical Faculty in an Academic Medical Center. Open Journal of Leadership, 6, 112-125.

https://doi.org/10.4236/ojl.2017.63008

Received: July 27, 2017

Accepted: August 19, 2017

Published: August 22, 2017

Copyright (c) 2017 by authors and Scientific Research Publishing Inc. This work is licensed under the Creative Commons Attribution International License (CC BY 4.0).

http://creativecommons.org/licenses/by/4.0/

\section{(c) (i) Open Access}

\begin{abstract}
Importance: With a shortage of surgeons, attrition of academic surgery faculty, especially junior faculty represents an organizational challenge. Objective: To profile surgical faculty attrition at one academic medical center and investigate whether differences in attrition exist over time between faculty ranks, genders or ethnic groups. Design, Setting, and Participants: The population included surgical faculty members who were employed in our academic medical center as of July 1, 1996, or were subsequently hired at least half-time through June 30, 2011. The primary analyses involved length of time to faculty departure during the study period. We applied Kaplan-Meier survival analysis methods, Cox Proportional Hazard Regression, and incidence rates of departure per 100 person-years. Main Outcomes and Measures: Using faculty rank as a time-varying covariate, we examined the association between time to departure and the following: faculty rank, gender, and race. Results: Among 302 members of the surgical faculty, almost $70 \%$ of whom entered the study period as assistant professors, the rate of departure was significantly higher for assistant professors compared to senior faculty ranks. Departure rates were not found to be different between gender or race groups. Conclusions and Relevance: The rate of departure over several decades was significantly higher for assistant professors compared to senior faculty ranks. Although estimates of surgeon shortages may vary, to remain competitive and establish a pipeline of future leaders, academic medical centers will not only have to recruit new surgeons to replace retirees, but will also have to work to retain surgeons at the earlier stages of their careers.
\end{abstract}

\section{Keywords}

Attrition, Shortage, Assistant Professor, Recruitment, Retention, Leadership, Surgery, Careers, Academic 


\section{Introduction}

The projected shortage of surgeons is attributed to problems of both supply and demand (Association of American Medical Colleges, 2016; Williams et al., 2009). Using population based calculations, Williams et al. have estimated shortages of 29,138 surgical specialists by 2030 (Williams et al., 2009). On the demand side, the Association of American Medical Colleges (AAMC) estimates that total physician demand will grow by 112,000 full-time equivalents and with static supply, the U.S. likely will have a shortage of between 23,100 and 31,600 surgical specialists by 2025. An analysis of the demand side also indicates that an aging population, growing disease burden, and expanded medical coverage under the Affordable Care Act will further increase demand for General Surgeons by $18 \%$ and Vascular Surgeons by 31\% by 2025 (Dall et al., 2013). This compares to increases in demand for adult primary care physicians of 13\% (Dall et al., 2013).

On the supply side, increases in physician retirement, and voluntary departures due to physician burnout are straining both academic and private health systems, making it difficult for them to meet patient care demand. For academic health centers (AHCs), the burden is compounded by the added responsibility of the teaching and research missions. Accordingly, managing the attrition of surgeons assumes greater importance for teaching hospitals.

The overall turnover rate in hospitals is trending upwards reaching a median of 13.4\% in 2015 (Vonderhaar, 2016). Healthcare is a labor-intensive enterprise, with easily quantifiable workforce metrics that are closely watched by hospital administration, faculty affairs and health system boards (Warren, 2015). Physician turnover is now at $6 \%-7 \%$, and while the expense of recruiting and loss of productivity is the motivator for reducing attrition, organizational and strategic implications are in many ways more salient than cost-reduction alone (Satiani et al., 2013; 2013 Physician Recruiting Survey: Annual Physician Retention Survey, 2013). In a 2008 study by Association of American Medical Colleges (AAMC), four of ten faculty members, and half of clinical faculty left their faculty position within ten years of their first appointment (Alexander \& Lang, 2008). Since the success of the AMC and its mission is dependent on an engaged and wellaligned faculty, retention of suitable surgical specialists is critical.

A prior study profiled surgery faculty attrition using data aggregated into five-year time periods (Satiani et al., 2013). The current follow-up study was intended to provide richer, more robust results since we were able to track individual faculty over the same time period using disaggregated, individual level data. The objective of this study was to profile surgery faculty attrition at one AMC by tracking employment data from date of hiring through departure or the conclusion of the study period; primarily investigating whether differences in attrition exist between faculty ranks, genders or race-ethnic groups, and secondarily comparing findings to the prior literature (Satiani et al., 2013).

\section{Methods}

Population and Database Development. We downloaded from our central $\mathrm{Hu}-$ 
man Resources management system, PeopleSoft (Oracle Incorporated, Pleasanton, CA), a roster of faculty. Inclusion required that faculty were compensated with at least 50\%-time employment (i.e. 0.5 Full Time Equivalent (FTE) and above). For purposes of the statistical analysis, we restricted our study period to 15 academic years, starting from Time Point 1-July 1, 1996 and extending to Time Point 2-June 30, 2011. We included all faculties who were employed as of Time Point 1 and added those who were hired through Time Point 2. Study subjects included faculty from all surgical departments in our college, including departments or divisions of: Cardiothoracic, Colon \& Rectal, General, Neurological, Pediatric, Plastic, Transplant, and Vascular Surgery; as well as Orthopedics, Otolaryngology, Ophthalmology, Obstetrics \& Gynecology, Trauma-Critical Care/Burn, and Urology. We removed MD-PhD faculty whose primary work activity was research (less than 0.5 FTE of clinical work) in addition to all non-physician faculty including basic science researchers, podiatrists and those faculty hired specifically into administrative positions without clinical care responsibilities (e.g. Dean). Fellows in, despite having faculty titles, were trainees with short-term contracts and were therefore removed as well. To validate the final product, the faculty roster was cross-referenced against annual reports provided by each department during the study period. We also verified faculty start dates to ensure that we were assessing faculty from the point of their original faculty appointment, as opposed to hire dates for residency or fellowship positions. In summary, only faculty who were employed as of July 1, 1996 or were subsequently hired as clinicians with at least 0.5 FTE clinical assignment through June 30, 2011 were included in the study data set. Since all data used for this study were obtained from public employment records, we did not seek approval for human subject's research from our Institutional Review Board.

Definition and Verification of Departures. Faculty departures during the study period were coded in the personnel system as voluntary resignation, retirement, became no-salary appointment (i.e. obtained employment elsewhere but maintained a voluntary relationship with the department), involuntary resignation, misconduct, death, disability or converted to part-time (less than 0.5 FTE). We further classified voluntary faculty departures according to where they went: another academic medicine institution, private or community practice, or left practice altogether due to retirement, disability, or death (RDD). We verified all departures and reclassifications through inspection of departmental personnel records and interviews with veteran faculty and staff, which resulted in a complete accounting for all faculty departures during the study period.

Data Analysis. Using the final database described above, we investigated the demographics and differences between gender groups, faculty rank, and raceethnicity groups (Table 1 and Table 2). Due to small numbers of faculty in raceethnicity categories besides white, we analyzed the race-ethnicity categories as white versus non-white. Preliminary analyses (descriptive statistics) seemed to indicate that attrition rates were similar across gender and race-ethnicity groups. 
Table 1. Faculty demographics at the beginning and the end of the study.

\begin{tabular}{|c|c|c|c|c|}
\hline \multirow{2}{*}{ Demographic variables } & \multicolumn{2}{|c|}{ Beginning of work experience } & \multicolumn{2}{|c|}{ End of work experience } \\
\hline & $\mathbf{N}$ & $\%$ & $\mathbf{N}$ & $\%$ \\
\hline Total & 302 & 100.0 & 302 & 100.0 \\
\hline \multicolumn{5}{|l|}{ Rank } \\
\hline Assistant & 210 & 69.5 & 163 & 54.0 \\
\hline Associate & 48 & 15.9 & 76 & 25.2 \\
\hline Full & 44 & 14.6 & 63 & 20.8 \\
\hline \multicolumn{5}{|l|}{ Gender } \\
\hline Female & 53 & 17.5 & 53 & 17.5 \\
\hline Male & 249 & 82.5 & 249 & 82.5 \\
\hline \multicolumn{5}{|l|}{ Race } \\
\hline Non-white & 57 & 18.9 & 57 & 18.9 \\
\hline White & 245 & 81.1 & 245 & 81.1 \\
\hline \multicolumn{5}{|l|}{ Department or division } \\
\hline Cardiothoracic & 27 & 8.9 & 27 & 8.9 \\
\hline Colon \& rectal & 4 & 1.3 & 4 & 1.3 \\
\hline General & 17 & 5.6 & 17 & 5.6 \\
\hline Neurological surgery & 21 & 7.0 & 21 & 7.0 \\
\hline OB/GYN & 49 & 16.2 & 49 & 16.2 \\
\hline Ophthalmology & 30 & 9.9 & 30 & 9.9 \\
\hline Orthopedics & 38 & 12.6 & 38 & 12.6 \\
\hline Otolaryngology & 27 & 8.9 & 27 & 8.9 \\
\hline Pediatrics & 13 & 4.3 & 13 & 4.3 \\
\hline Plastics & 15 & 5.0 & 15 & 5.0 \\
\hline Surgical oncology & 19 & 6.3 & 19 & 6.3 \\
\hline Transplant & 7 & 2.3 & 7 & 2.3 \\
\hline Trauma, critical care/burn & 9 & 3.0 & 9 & 3.0 \\
\hline Urology & 16 & 5.3 & 16 & 5.3 \\
\hline Vascular & 10 & 3.3 & 10 & 3.3 \\
\hline
\end{tabular}

The primary analyses involved time to departure since the faculty had various lengths of employment during the study period. We applied Kaplan-Meier survival analysis methods, Cox Proportional Hazard Regression, and incidence rates of departure per 100 person-years to determine the association between time to departure and the following demographics: faculty rank, gender, and race (white versus non-white). Unfortunately, due to the number of departments involved, we were unable to test whether departments differed with regard to rates of departure. Rank was entered into the data as a time-varying covariate since a surgeon's rank could change with time. In survival analysis, this has the effect of adjusting the statistical model for changes in rank over time. The incidence of departure rates was estimated for three equally spaced time intervals for 
Table 2. Number and percentage of faculty promotions broken down by department.

\begin{tabular}{ccccc}
\hline \multirow{2}{*}{ Department or division } & \multicolumn{2}{c}{ Number \& percentage of promotions } & \multirow{2}{*}{ Total $^{*}$} \\
\cline { 2 - 4 } & None & 1 & 2 & \\
\hline Cardiothoracic surgery & $27(77.1 \%)$ & $7(20 \%)$ & $1(3 \%)$ & $35(9.5 \%)$ \\
Colon \& rectal surgery & $4(80 \%)$ & $1(20 \%)$ & $0(0 \%)$ & $5(1.4 \%)$ \\
General surgery & $17(70.8 \%)$ & $6(25 \%)$ & $1(4.2 \%)$ & $24(6.5 \%)$ \\
Neurological surgery & $21(91.3 \%)$ & $2(8.7 \%)$ & $0(0 \%)$ & $23(6.3 \%)$ \\
Obstetrics/gynecology & $49(83.1 \%)$ & $9(15.3 \%)$ & $1(1.7 \%)$ & $59(16 \%)$ \\
Ophthalmology & $30(96.8 \%)$ & $1(3.2 \%)$ & $0(0 \%)$ & $31(8.4 \%)$ \\
Orthopedics & $37(84.1 \%)$ & $5(11.4 \%)$ & $1(2.3 \%)$ & $44(12 \%)$ \\
Otolaryngology & $27(81.8 \%)$ & $6(18.2 \%)$ & $0(0 \%)$ & $33(9 \%)$ \\
Pediatric surgery & $13(68.4 \%)$ & $5(26.3 \%)$ & $1(5.3 \%)$ & $19(5.2 \%)$ \\
Plastic surgery & $15(78.9 \%)$ & $4(21.1 \%)$ & $0(0 \%)$ & $19(5.2 \%)$ \\
Surgical oncology & $19(79.2 \%)$ & $5(20.8 \%)$ & $0(0 \%)$ & $24(6.5 \%)$ \\
Transplant & $7(50 \%)$ & $5(35.7 \%)$ & $2(14.3 \%)$ & $14(3.8 \%)$ \\
Trauma, critical care/burn & $9(90 \%)$ & $1(10.0 \%)$ & $0(0 \%)$ & $10(2.7 \%)$ \\
Urology & $16(100 \%)$ & $0(0 \%)$ & $0(0 \%)$ & $16(4.3 \%)$ \\
Vascular surgery & $10(83.3 \%)$ & $2(16.7 \%)$ & $0(0 \%)$ & $12(3.3 \%)$ \\
Total & $301(82 \%)$ & $59(16.1 \%)$ & $7(1.9 \%)$ & $367(100 \%)$ \\
\hline
\end{tabular}

${ }^{*}$ Percentage of total promotions.

the first nine years plus a fourth interval of greater than nine years. All analyses were completed using Stata, Version 14.1 (StataCorp, College Station, TX).

In Table 3, Column 2, "Person-years", is the number of years that faculty in each category were employed (i.e. number of years the individual worked until the end of the study period or until they departed) multiplied by the number of faculty subjects. For example, if Faculty A was hired as an assistant professor on July 1,2000, and remained employed for the remainder of the study period, he/she would be credited with 11 total years of employment. We would multiply all of the faculty years in the study by the total number of faculty in that category for that specific time interval to arrive at Person-years. Departures (Column 3) represent the number of faculty who departed during that time interval. The breakdown of time intervals in Column 1: (0 - 3], (3 - 6], etc. were chosen for ease of reporting. "The rate per 100 person-years" (Column 4) can be interpreted as an estimate of the number of departures per 100 years of time; in other words, the larger the number, the higher the rate of departure. Finally, Column 5 represents the $95 \%$ Confidence Interval in estimating the rate per 100 person-years.

Finally, to explain where departing faculty went, we conducted post-hoc analyses (Chi-Square Analyses) comparing the relationship between the type of practice entered upon leaving and demographic variables: academic medicine, private practice, or left practice and the demographic variables: gender, raceethnicity, and faculty rank when departing. 
Table 3. Rates of resignation (departures) per 100 person-years of time by faculty demographics.

\begin{tabular}{|c|c|c|c|c|c|}
\hline $\begin{array}{c}\text { Demographics } \\
\text { Assistant }\end{array}$ & Person-years & Departures* & Rate per 100 person-years & \multicolumn{2}{|c|}{$95 \% \mathrm{CI}$} \\
\hline$(0-3]$ & 548.18 & 28 & 5.11 & 3.53 & 7.40 \\
\hline$(3-6]$ & 307.56 & 23 & 7.48 & 4.97 & 11.25 \\
\hline$(6-9]$ & 127.62 & 11 & 8.62 & 4.77 & 15.56 \\
\hline$>9$ & 121.33 & 2 & 1.65 & 0.41 & 6.59 \\
\hline All & 1104.69 & 64 & 5.79 & 4.53 & 7.40 \\
\hline \multicolumn{6}{|l|}{ Associate } \\
\hline$(0-3]$ & 134.84 & 3 & 2.22 & 0.72 & 6.90 \\
\hline$(3-6]$ & 113.01 & 1 & 0.88 & 0.12 & 6.28 \\
\hline$(6-9]$ & 137.38 & 5 & 3.64 & 1.51 & 8.74 \\
\hline$>9$ & 477.44 & 8 & 1.68 & 0.84 & 3.35 \\
\hline All & 862.66 & 17 & 1.97 & 1.23 & 3.17 \\
\hline \multicolumn{6}{|l|}{ Full } \\
\hline$(0-3]$ & 118.99 & 2 & 1.68 & 0.42 & 6.72 \\
\hline$(3-6]$ & 92.81 & 2 & 2.15 & 0.54 & 8.62 \\
\hline$(6-9]$ & 77.08 & 2 & 2.59 & 0.65 & 10.37 \\
\hline$>9$ & 499.63 & 4 & 0.80 & 0.30 & 2.13 \\
\hline All & 788.51 & 10 & 1.27 & 0.68 & 2.36 \\
\hline \multicolumn{6}{|l|}{ Female } \\
\hline$(0-3]$ & 136.49 & 9 & 6.59 & 3.43 & 12.67 \\
\hline$(3-6]$ & 78.79 & 2 & 2.54 & 0.63 & 10.15 \\
\hline$(6-9]$ & 48.03 & 1 & 2.08 & 0.29 & 14.78 \\
\hline$>9$ & 120.83 & 1 & 0.83 & 0.12 & 5.88 \\
\hline All & 384.15 & 13 & 3.38 & 1.97 & 5.83 \\
\hline \multicolumn{6}{|l|}{ Male } \\
\hline$(0-3]$ & 665.52 & 24 & 3.61 & 2.42 & 5.38 \\
\hline$(3-6]$ & 434.59 & 24 & 5.52 & 3.70 & 8.24 \\
\hline$(6-9]$ & 294.05 & 17 & 5.78 & 3.59 & 9.30 \\
\hline$>9$ & 977.57 & 13 & 1.33 & 0.77 & 2.29 \\
\hline All & 2371.72 & 78 & 3.29 & 2.63 & 4.11 \\
\hline \multicolumn{6}{|l|}{ Non-white } \\
\hline$(0-3]$ & 154.60 & 8 & 5.17 & 2.59 & 10.35 \\
\hline$(3-6]$ & 85.71 & 5 & 5.83 & 2.43 & 14.01 \\
\hline$(6-9]$ & 42.17 & 5 & 11.86 & 4.93 & 28.48 \\
\hline$>9$ & 84.42 & 0 & 0.00 & & \\
\hline All & 366.91 & 18 & 4.91 & 3.09 & 7.79 \\
\hline \multicolumn{6}{|l|}{ White } \\
\hline$(0-3]$ & 647.40 & 25 & 3.86 & 2.61 & 5.71 \\
\hline
\end{tabular}


Continued

\begin{tabular}{cccccc}
\hline (3 - 6] & 427.66 & 21 & 4.91 & 3.20 & 7.53 \\
$(6-9]$ & 299.91 & 13 & 4.33 & 2.52 & 7.47 \\
$>9$ & 1013.98 & 14 & 1.38 & 0.82 & 2.33 \\
All & 2388.95 & 73 & 3.06 & 2.43 & 3.84 \\
\hline Department & & & & \\
\hline Cardiothoracic & 163.45 & 15 & 9.18 & 5.53 & 15.22 \\
Colon \& rectal & 34.66 & 1 & 2.88 & 0.41 & 20.48 \\
General & 159.18 & 7 & 4.40 & 2.10 & 9.22 \\
Neurological surgery & 136.31 & 4 & 2.93 & 1.10 & 7.82 \\
Obstetrics/gynecology & 588.82 & 12 & 2.04 & 1.16 & 3.59 \\
Ophthalmology & 432.26 & 7 & 1.62 & 0.77 & 3.40 \\
Orthopedics & 220.16 & 17 & 7.72 & 4.80 & 12.42 \\
Otolaryngology & 233.34 & 3 & 1.29 & 0.41 & 3.99 \\
Pediatrics & 103.45 & 4 & 3.87 & 1.45 & 10.30 \\
Plastics & 129.85 & 4 & 3.08 & 1.16 & 8.21 \\
Surgical oncology & 186.26 & 5 & 2.68 & 1.12 & 6.45 \\
Transplant & 121.41 & 0 & 0.00 & & \\
Trauma, critical care/burn & 48.48 & 2 & 4.13 & 1.03 & 16.49 \\
Urology & 105.20 & 6 & 5.70 & 2.56 & 12.69 \\
Vascular & 93.03 & 4 & 4.30 & 1.61 & 11.46 \\
\hline Total & 2755.87 & 91 & 3.30 & 2.69 & 4.06 \\
\hline & & & & & \\
\hline & & & & & \\
\hline
\end{tabular}

*Time to resignation.

\section{Results}

The resulting database contained 302 unique faculty surgeons who were considered active, full-time employees during the study period. Two hundred ten (69.5\%) entered the study period at the rank of assistant professor, 48 (15.9\%) as associate professor, and $44(14.6 \%)$ as full professor (Table 1). The faculty were predominantly male $(82.5 \%)$, and white $(81.1 \%)$. The departments or divisions with the largest percentage of faculty were Obstetrics/Gynecology (16.2\%), Orthopedics (12.6\%), Ophthalmology (9.9\%) Cardiothoracic Surgery (8.9\%) and Otolaryngology (8.9\%). Nearly $20 \%$ (60 of 302) of all faculty members in the dataset were promoted at least once during the study period and $2.3 \%$ (7 of 302) were promoted twice (Table 2).

Table 3 shows the results of the Kaplan-Meier Analyses which, suggests that the rates of departure were significantly higher for assistant professors compared to other faculty ranks; higher for women in the first three years of employment, and higher for men over the second two time intervals ((3 - 6] and (6-9]); and higher for non-white faculty during the third interval ((6 - 9]).

The Cox proportional hazard regression analysis was used to test the hypotheses that the independent variables (rank, gender, and race (white versus 
non-white)) differed with regard to rates of departure (Table 3 and Figures 1-3). We observed no significant interactions between independent variables, so only the main effects are shown in Table 4.

When looking at Figure 1, the Kaplan-Meier survival curves for time to resignation (departure) by rank, the attrition rate (or cumulative proportion of survival) accelerates more rapidly for assistant professors than it does for associate or full professors. The Cox proportional hazard regression test determined that the only significant difference between departure rates by rank was observed between assistant and full professors (Log-rank $p$ value $<0.001, \mathrm{HR}=3.09, p=0.002$ ).

Figure 2 shows the Kaplan-Meier survival curves for time to resignation (departure) by gender. These curves appear different past the 5 -year interval. However,

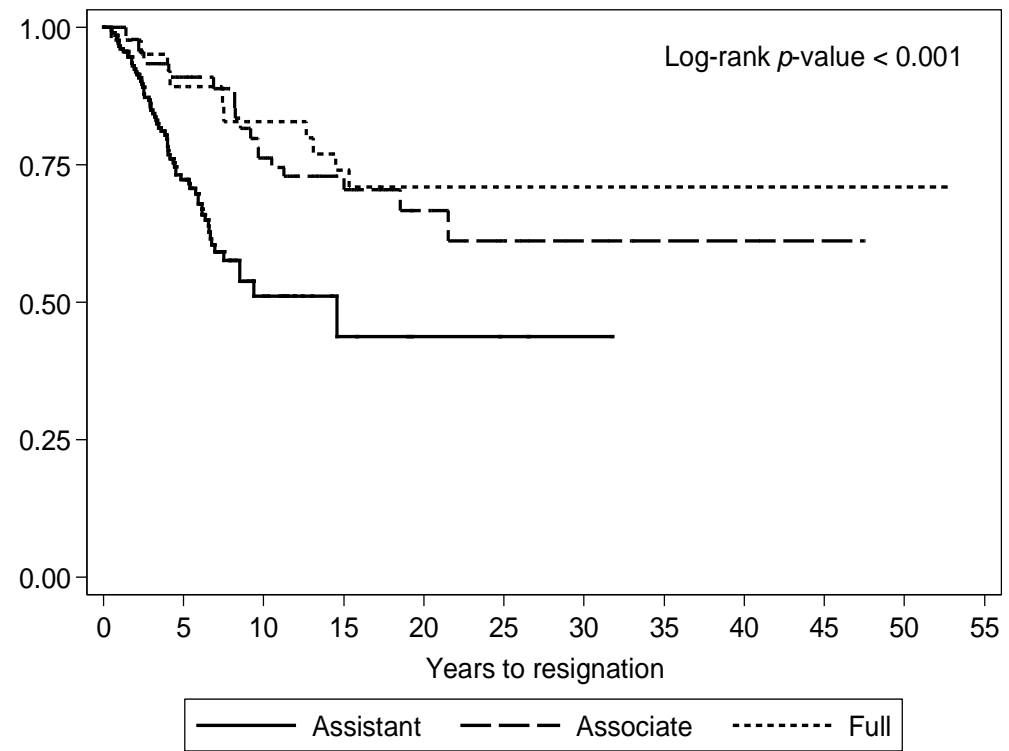

Figure 1. Kaplan-Meier time to resignation by rank.

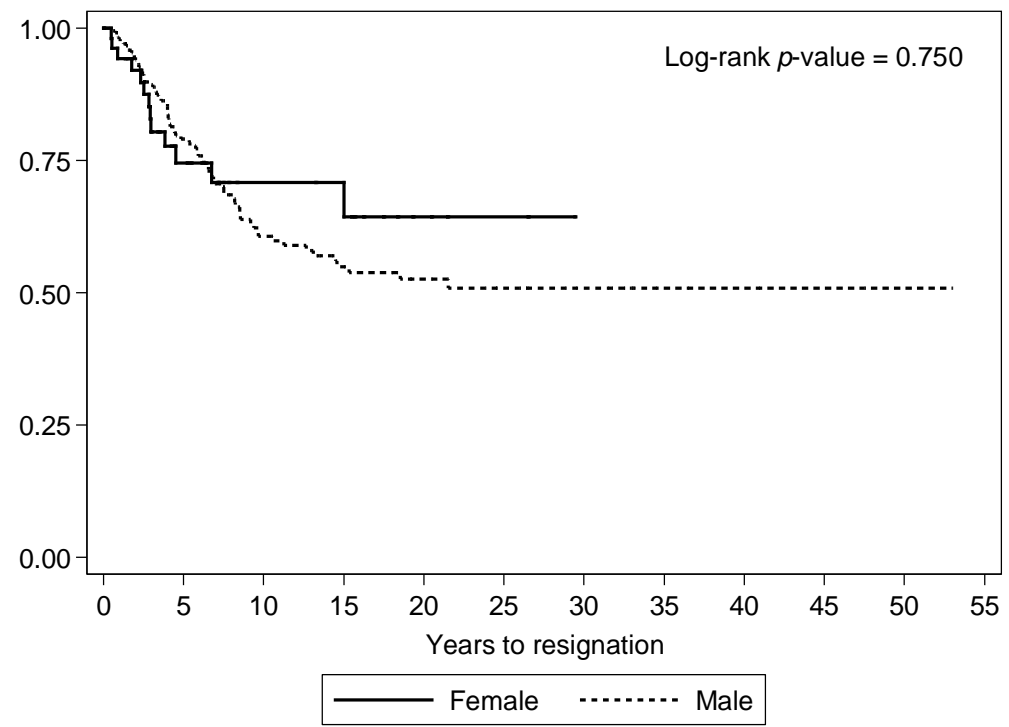

Figure 2. Kaplan-Meier time to resignation by gender. 


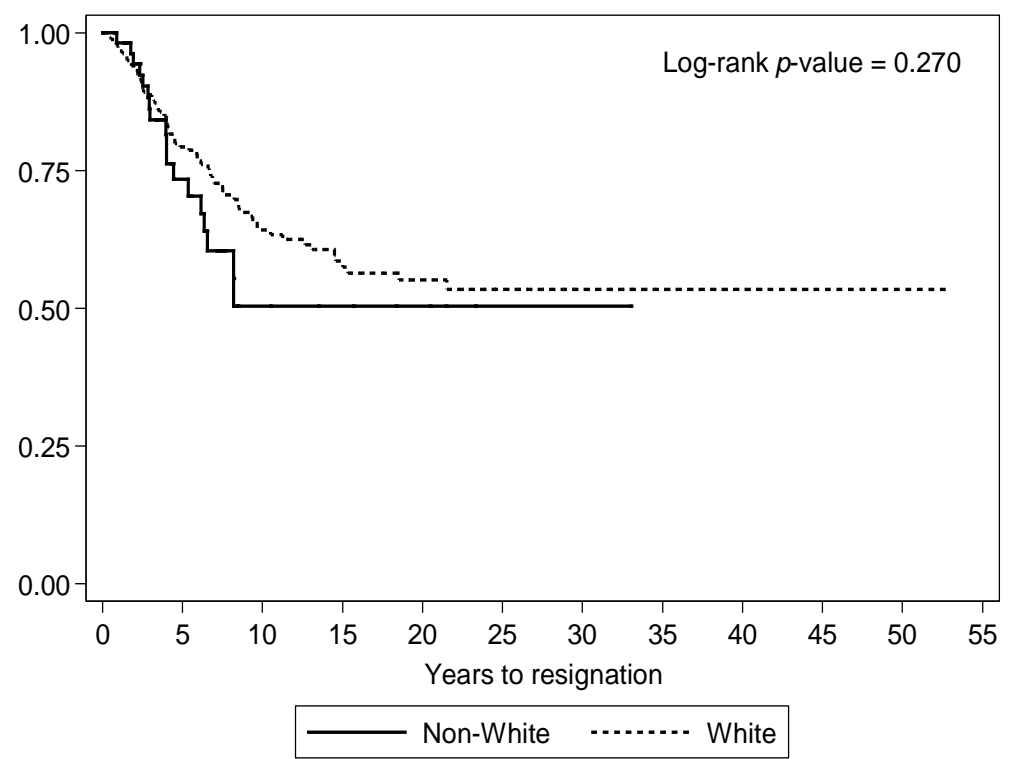

Figure 3. Kaplan-Meier time to resignation by race/ethnicity.

Table 4. Resignation hazard ratios from a cox proportional hazard regression (ignoring the interaction).

\begin{tabular}{cccc}
\hline Term & HR & $95 \%$ CI & $P$-value \\
\hline Assistant vs. full & 3.09 & $1.52-6.29$ & 0.002 \\
Associate vs. full & 1.29 & $0.59-2.83$ & 0.529 \\
Male vs. female & 1.38 & $0.76-2.51$ & 0.292 \\
Non-white vs. white & 1.19 & $0.70-2.02$ & 0.529 \\
\hline
\end{tabular}

they were found not to be statistically different (Log-rank $p$ value $=0.750, \mathrm{HR}=$ 1.38, $p=0.292$ ). As can be seen in Figure 3, the attrition rate was also determined not to be significantly different for whites vs. non-whites (Log-rank $p$ value $=0.270, \mathrm{HR}=1.19, p=0.529$ ).

During the 15-year study period, slightly more than a third (107 of 302, 35.4\%) of the total faculty departed from their faculty position at The Ohio State University Department of Surgery. Most of these faculty departed for private practice (59 of 107, 55.1\%). Slightly more than a quarter remained in academic medicine ( 28 of 107, 26.2\%). The remainder (20 of 107, 18.7\%) either retired, became disabled, or were deceased (RDD).

There were no statistical differences between males and females with regard to departure for academic or private practice $\left(X^{2}=0.22 ; \mathrm{df}=2, p=0.90\right)$. However, we found that a larger-than-expected proportion of non-white faculty remained in academic medicine while a larger-than-expected proportion of white faculty became $\operatorname{RDD}\left(X^{2}=5.92 ; \mathrm{df}=2, p=0.05\right)$. Finally, we observed that assistant professors who departed were more likely to go into private practice, while full professors were more likely to become $\operatorname{RDD}\left(X^{2}=29.6, \mathrm{df}=4, p \leq 0.001\right.$; see Table 5). 
Table 5. Demographic characteristics and statistical analysis of 170 academic physicians who departed the department of surgery during the study period July 1, 1996 to June 30, 2011 by reason for leaving.

\begin{tabular}{|c|c|c|c|}
\hline Characteristic (N) & Leaving for academic medicine & Leaving for private practice & Retired, disabled, deceased \\
\hline \multicolumn{4}{|l|}{ Gender } \\
\hline Female (14) & $4(28.6)$ & $8(57.1)$ & $2(14.3)$ \\
\hline Male (93) & $24(25.8)$ & $51(54.8)$ & $18(19.4)$ \\
\hline Total (107) & 28 of $107(26.2)$ & 59 of $107(55.1)$ & 20 of 107 (18.7) \\
\hline Chi-Square analysis results & & $X^{2}=0.22 ; \mathrm{df}=2 ; p=0.90$ & \\
\hline \multicolumn{4}{|l|}{ Race/ethnicity* } \\
\hline Non-White (20) & $9(45.0)$ & $10(50.0)$ & $1(5.0)$ \\
\hline White (87) & $19(21.8)$ & $49(56.3)$ & $19(21.8)$ \\
\hline Total (107) & 28 of $107(26.2)$ & 59 of $107(55.1)$ & 20 of $107(18.7)$ \\
\hline Chi Square analysis results & & $X^{2}=5.92 ; \mathrm{df}=2 ; p=0.05$ & \\
\hline \multicolumn{4}{|l|}{ Rank at departure } \\
\hline Assistant professor (66) & $19(28.8)$ & $44(66.7)$ & $3(4.5)$ \\
\hline Associate professor (24) & $5(20.8)$ & $12(50.0)$ & $7(29.2)$ \\
\hline Full professor (17) & $4(23.5)$ & $3(17.6)$ & $10(58.8)$ \\
\hline Total (107) & 28 of $107(26.2)$ & 59 of $107(55.1)$ & 20 of $107(18.7)$ \\
\hline Chi-Square analysis results & & $X^{2}=29.6 ; \mathrm{df}=4 ; p<0.001$ & \\
\hline
\end{tabular}

\section{Discussion}

This study of 302 surgical faculty, almost $70 \%$ of whom entered the study period as assistant professors, demonstrated that the rate of departure was significantly higher for assistant professors compared to senior faculty ranks. Furthermore, departing assistant professors were more likely to leave academic medicine for private practice when compared to other ranks (Table 5). We also observed that a significantly higher percentage of white faculty left for private practice than remained in academic medicine, whereas the percentages of non-white faculty were nearly equally split between those who went into private practice and those who remained in academic medicine.

Our previous study of faculty attrition led us to conclude that attrition rates were higher for more senior faculty, but only for the time period 2006-2011 (Satiani et al., 2013). Data for that study was obtained in aggregate form from the AAMC Faculty Administrative Management On-Line User System (FAMOUS) database, making it difficult to track individual faculty members over time. Furthermore, the nature of the FAMOUS database, which relies on institutional self-reported data, is perhaps not sufficiently reliable compared to the data collection procedures used in this study, which included longitudinal accounting of each faculty member from an internal software tracking system cross-referenced against departmental reports as well as verification by veteran faculty and staff.

Success in retaining faculty starts with effective recruiting. A distinct effort by the institution at the front end on what constitutes a good fit for the local culture 
pays dividends in the long run. Lost in the hasty effort to replace departing surgeons in vital specialties, recruitment is often reactionary and may result in poor choices, with financial and strategic considerations becoming an afterthought. Strategic planning lays out a plan for hospitals about the direction they need to go and ways to get there. Which specialties are growing? Where is new technology proliferating? Where are workforce shortages likely to be most severe? Which specialties at the AMC are heavily weighted towards older faculty and need replenished? What are the expressed needs of junior faculty? Rather than wait for faculty departure, department and division heads must have a proactive, longitudinal ( 2 - 10 years) recruitment plan. Although, most hospital planning groups or human resources departments have faculty complete a brief survey often annually to estimate demand in their specialty, this feeble effort is more suited for budgetary purposes. To use this information to gauge recruitment needs will not suffice in an era of competition for many surgical specialties. Finally, useful information must be gathered from departing surgeons to allow recalibration of any retention strategy. Some have proposed "stay" interviews rather than an exit interview to gauge career satisfaction and early intervention to avoid productive faculty departures (Keyser, 2014). Exit interviews have only been done at our institution for the past three years. Approximately $50 \%$ of departing faculty have agreed to either face-to-face interviews or electronic surveys. Preliminary data show that most departures are due to dissatisfaction related to stress associated with productivity demands or unhappiness with the institutional culture.

Physician engagement tactics and retention strategies may differ depending on the generation or age group being targeted. Younger physicians are the most vulnerable to turnover between one and three years after employment with an aggregate turnover of $25 \%$ in the first three years of employment (Gramer, 2015). Younger faculties are also more likely to consider leaving academic medicine due to dissatisfaction (Pololi et al., 2009). In a survey of physician engagement, Generation Xers demonstrated the lowest level of engagement whereas "traditionalists" represented the most engaged group of physicians with baby boomers in between (Kaissi, 2016). Junior faculty likewise had a significantly lower satisfaction rate with their medical school as a workplace compared to senior faculty (65\% versus $59 \%, p<0.004)$ (Wai et al., 2014).

In a faculty forward engagement survey of 1356 surgeons Wai and colleagues reported that department governance, collegiality, collaboration, and relationship with their supervisor were the strongest predictors of overall satisfaction, demonstrating that faculty satisfaction with the medical school was primarily driven by workplace culture (Wai et al., 2014). To retain younger faculty, proper initial selection and recruitment, in addition to maintaining a nurturing culture are important (Vonderhaar, 2016; Satiani et al., 2013; Gramer, 2015; Pololi et al., 2009; Wai et al. 2014). Among other reasons, dissatisfaction due to failure to be promoted may be a cause of younger faculty leaving academic medicine. In 2010, the AAMC reported that the average number of years to promotion for medical 
school faculty was 6.2 years for faculty who started careers in academic medicine between 1987 and 1996 (Liu, 2010). Our own institution's average years to promotion is slightly higher than that at seven years. During our study period, we estimated that 59 of 302 faculty (19.5\%) were promoted. While we are unable to isolate whether faculty departed because they were not promoted; we are able to surmise that since most assistant professor faculty left within the first six years of employment that lack of promotion may have factored into reasons for their departure. Chen et al. surveyed 83 programs in Plastic Surgery to evaluate trends in recruitment and retention of faculty. Thirty four of 56 programs $(60.7 \%)$ responding indicated that faculty departed because of inadequate compensation (Vonderhaar, 2016). Furthermore, $79 \%$ of 59 programs indicated that most faculty left academic surgery altogether. Although, compensation is not the primary reason for faculty departures, it has been shown to be statistically correlated to academic surgeon satisfaction (Chen et al., 2014).

As necessary as it is to retain younger faculty, older faculty now comprise a third of the current faculty workforce, and they have different needs, attitudes and goals. This is a growing trend. In 2007 one-third of faculty was over 55 years of age compared to $10 \%$ in 1967 and 20\% in1987 (Mallon \& Buckley, 2012). There are some specific approaches to retain senior faculty including sustained salary support, research support, support for clinical educators, recognition of clinical and teaching service, participation in departmental and institutional governance (Lowenstein, Fernandez, \& Crane, 2007).

As learning organizations, AMC's are in a unique position to offer faculties growth and development opportunities for future leaders, and must therefore urge their surgeons to view their careers and lives through a much wider lens than monetary rewards. A winning option, among several, in retaining high potential physicians and other faculty is offering leadership training and other forms of development to support faculty in advancing their careers (Satiani et al., 2014). Ries et al. reported that 120 participants in a new assistant professor faculty retention program funded through a National Centers of Leadership in Academic Medicine award were $67 \%$ more likely to remain at the University of California, San Diego compared to non-participants (Ries et al., 2009).

Limitations. These findings are from a single, mid-western United States institution over several decades and while our analyses included decades of employment data, these findings may not be applicable to other institutions. Additionally, there were many infrastructure and leadership changes over time, which may have influenced departures, as well as other institution-specific historic events. With respect to Assistant Professors in particular, it is understood that some departures are "good" in the sense that they are moving due to promotions or being recruited elsewhere. Finally, our study period was limited to the fifteen years ending in 2011 due mainly to delay in obtaining data from various sources and tracing department members. However, we believe that based on a preliminary analysis of departures since 2011, the attrition trends we ob- 
served during that period persist today.

\section{Conclusion}

This study demonstrates that the rate of departure over an extended period of time was significantly higher for assistant professors in surgery compared to senior faculty ranks, and that assistant professors were more commonly leaving academic medicine for private practice. Although drastic changes in models of care and technology may alter some of the estimates of surgeon shortages, it is clear that AMC's must remain competitive in replenishing retiring surgeons for leadership roles with a limited supply of qualified newly graduating surgeons. Furthermore, effective recruitment and retention of the new assistant professor must be part of any multi-pronged plan towards strategic, organizational and financial success of the AMC.

\section{Acknowledgements}

None of the authors have any conflicts of interest, including relevant financial interests, activities, relationships, and affiliations. The authors report no proprietary or commercial interest in any product mentioned or concept discussed in this article. The authors also have not received any financial or material support for the research and this work. The corresponding author Bhagwan Satiani and David Way, a co-author, have had full access to all the data in the study and take responsibility for the integrity of the data and the accuracy of the data analysis. The authors have not presented or published the information from this study previously. A study from a different database with dissimilar methodology has been discussed in the manuscript.

\section{References}

2013 Physician Recruiting Survey: Annual Physician Retention Survey. https://www.cejkasearch.com/survey/physician-recruiting-survey-annual-physician-ret ention

Alexander, H., \& Lang, J. (2008). The Long-Term Retention and Attrition of U.S. Medical School Faculty. Analysis in Brief (pp. 1-2). Washington DC: Association of American Medical Colleges.

Association of American Medical Colleges (2016). The Complexities of Physician Supply and Demand: Projections from 2013 to 2025.

https://www.aamc.org/download/426242/data/ihsreportdownload.pdf?cm_mmc=AAM C-_-ScientificAffairs-__PDF-_-ihsreport

Chen, J. T., Girotto, J. A., Kitzmiller, W. J., Lawrence, W. T., Verheyden, C. N., Vedder, N. B., Coleman, J. J., \& Bentz, M. L. (2014). Academic Plastic Surgery: Faculty Recruitment and Retention. Plastic and Reconstructive Surgery, 133, 393e-404e. https://doi.org/10.1097/01.prs.0000438045.06387.63

Dall, T. M., Gallo, P. D., Chakrabarti, R., Terry, W., \& Semilla, A. P. (2013). An Aging Population and Growing Disease Burden Will Require a Large and Specialized Health Care Workforce by 2025. Health Affair, 32, 2013-2020.

https://doi.org/10.1377/hlthaff.2013.0714 
Gramer, G. (2015). Recruiting Physicians Today (pp. 1-4). Waltham, MA: NEJM CareerCenter.

http://employer.nejmcareercenter.org/rpt/RecruitingPhysiciansToday_JanFeb15.pdf

Kaissi, A. A. (2016). Roadmap for Trust: Enhancing Physician Engagement. http://www.cp-net.ca/site/ywd_dd_76/assets/pdf/a_roadmap_for_trust_with_cover_ preface_-_lb_rev.pdf

Keyser, J. (2014). Conversation and Stay Interviews Are the Work of a Leader. http://smartblogs.com/leadership/2014/04/30/conversations-and-stay-interviews-are-t he-work-of-a-leader/?utmsource=brief

Liu, C. Q., \& Alexander, H. (2010). Analysis in Brief. Washington DC: Association of American Medical Colleges.

https://www.aamc.org/download/121130/data/aibvol9_no7.pdf

Lowenstein, S. R., Fernandez, G., \& Crane, L. A. (2007). Medical School Faculty Discontent: Prevalence and Predictors of Intent to Leave Academic Careers. BMC Medical Education, 7, 37. https://doi.org/10.1186/1472-6920-7-37

Mallon, W. T., \& Buckley, P. F. (2012). The Current State and Future Possibilities of Recruiting Leaders of Academic Health Centers. Academic Medicine, 87, 1171-1176. https://doi.org/10.1097/ACM.0b013e31826155f6

Pololi, L., Kern, D. E., Carr, P., Conrad, P., \& Knight, S. (2009). The Culture of Academic Medicine: Faculty Perceptions of the Lack of Alignment between Individual and Institutional Values. Journal of General Internal Medicine, 24, 1289-1295. https://doi.org/10.1007/s11606-009-1131-5

Ries, A., Wingard, D., Morgan, C., Farrell, E., Letter, S., \& Reznick, V. (2009). Retention of Junior Faculty in Academic Medicine at the University of California, San Diego. Academic Medicine, 84, 37-41. https://doi.org/10.1097/ACM.0b013e3181901174

Satiani, B., Sena, J., Ruberg, R., \& Ellison, E. C. (2014). Talent Management and Physician Leadership Training Is Essential for Preparing Tomorrow's Physician Leaders. Journal of Vascular Surgery, 59, 542-546. https://doi.org/10.1016/j.jvs.2013.10.074

Satiani, B., Williams, T. E., Brod, H., Way, D. P., \& Ellison, E. C. (2013) A Review of Trends in Attrition Rates for Surgical Faculty: A Case for a Sustainable Retention Strategy to Cope with Demographic and Economic Reality. Journal of the American College of Surgeons, 216, 944-953. https://doi.org/10.1016/j.jamcollsurg.2012.12.052

Vonderhaar, K. (2016). Stop Turnover in the First Three Years. The Advisory Board. https://www.advisory.com/research/hr-advancement-center/studies/2016/stop-turnove r-in-the-first-three-years

Wai, P. Y., Dandar, V., Radosevich, D. M., Brubaker, L., \& Kuo, P. C. (2014). Engagement, Workplace Satisfaction, and Retention of Surgical Specialists in Academic Medicine in the United States. Journal of the American College of Surgeons, 219, 31-42. https://doi.org/10.1016/j.jamcollsurg.2014.03.027

Warren, B. (2015). Turnover: The Cost, the Causes and a Sustainable Solution. http://www.selectinternational.com/turnover-the-cost-the-causes-and-a-sustainable-so $\underline{\text { lution }}$

Williams, T. E., Satiani, B., Thomas, A., \& Ellison, C. E. (2009). The Impending Shortage and the Estimated Cost of Training the Future Surgical Workforce. Annals of Surgery, 250, 590-597. https://doi.org/10.1097/SLA.0b013e3181b6c90b 
Submit or recommend next manuscript to SCIRP and we will provide best service for you:

Accepting pre-submission inquiries through Email, Facebook, LinkedIn, Twitter, etc. A wide selection of journals (inclusive of 9 subjects, more than 200 journals)

Providing 24-hour high-quality service

User-friendly online submission system

Fair and swift peer-review system

Efficient typesetting and proofreading procedure

Display of the result of downloads and visits, as well as the number of cited articles Maximum dissemination of your research work

Submit your manuscript at: http://papersubmission.scirp.org/

Or contact ojl@scirp.org 